Article

\title{
Impact of Pre-Pregnancy BMI on B Vitamin and Inflammatory Status in Early Pregnancy: An Observational Cohort Study
}

\author{
Anne-Lise Bjørke-Monsen ${ }^{1, *}$, Arve Ulvik ${ }^{2}$, Roy M. Nilsen ${ }^{3}$, Øivind Midttun ${ }^{2}$, \\ Christine Roth ${ }^{4,5}$, Per Magnus ${ }^{4}$, Camilla Stoltenberg ${ }^{4,6}$, Stein Emil Vollset ${ }^{4,6}$, \\ Ted Reichborn-Kjennerud ${ }^{4,7}$ and Per Magne Ueland ${ }^{1,8}$ \\ 1 Laboratory of Clinical Biochemistry, Haukeland University Hospital, 5021 Bergen, Norway; \\ per.ueland@ikb.uib.no \\ 2 Bevital AS, 5021 Bergen, Norway; Arve.Ulvik@uib.no (A.U.); oivind.midttun@bevital.no (Ø.M.) \\ 3 Centre for Clinical Research, Haukeland University Hospital, 5021 Bergen, Norway; Roy.Nilsen@uib.no \\ 4 The Norwegian Institute of Public Health, 0403 Oslo, Norway; Christine.Roth@fhi.no (C.R.); \\ Per.Magnus@fhi.no (P.M.); camilla.stoltenberg@fhi.no (C.S.); SteinEmil.Vollset@fhi.no (S.E.V.); \\ Ted.Reichborn-Kjennerud@fhi.no (T.R.-K.) \\ 5 Nic Waals Institute, Lovisenberg Hospital, Oslo 0456, Norway \\ 6 Department of Public Health and Primary Health Care, University of Bergen, 5007 Bergen, Norway \\ 7 Institute of Clinical Medicine, University of Oslo, 0313 Oslo, Norway \\ 8 Department of Clinical Science, University of Bergen, 5007 Bergen, Norway \\ * Correspondance: almo@helse-bergen.no; Tel.: +47-559-730-87; Fax: +47-559-731-15
}

Received: 8 September 2016; Accepted: 28 November 2016; Published: 30 November 2016

\begin{abstract}
Maternal nutrition and inflammation have been suggested as mediators in the development of various adverse pregnancy outcomes associated with maternal obesity. We have investigated the relation between pre-pregnancy BMI, B vitamin status, and inflammatory markers in a group of healthy pregnant women. Cobalamin, folate, pyridoxal $5^{\prime}$-phosphate, and riboflavin; and the metabolic markers homocysteine, methylmalonic acid, and 3-hydroxykynurenine/xanthurenic acid ratio (HK/XA); and markers of cellular inflammation, neopterin and kynurenine/tryptophan ratio (KTR) were determined in pregnancy week 18 and related to pre-pregnancy body mass index (BMI), in 2797 women from the Norwegian Mother and Child Cohort Study (MoBa). Pre-pregnancy BMI was inversely related to folate, cobalamin, pyridoxal $5^{\prime}$-phosphate (PLP), and riboflavin $(p<0.001)$, and associated with increased neopterin and KTR levels $(p<0.001)$. Inflammation seemed to be an independent predictor of low vitamin B6 status, as verified by low PLP and high HK/XA ratio. A high pre-pregnancy BMI is a risk factor for low $B$ vitamin status and increased cellular inflammation. As an optimal micronutrient status is vital for normal fetal development, the observed lower B vitamin levels may contribute to adverse pregnancy outcomes associated with maternal obesity and B vitamin status should be assessed in women with high BMI before they get pregnant.
\end{abstract}

Keywords: pregnancy; obesity; pre-pregnancy BMI; B vitamins; inflammation

\section{Introduction}

There is an increasing prevalence of obesity in most parts of the world, also affecting women of childbearing age [1]. Pre-pregnancy obesity is associated with an increased risk of adverse pregnancy outcomes for both mother and child, including subfertility, miscarriage, gestational diabetes, gestational hypertension, preeclampsia, macrosomia, preterm birth, congenital anomalies, and fetal death [2,3]. Epidemiological studies have revealed strong links between nutritional excess during pregnancy and later development of metabolic disease, such as type 2 diabetes and obesity, in adult 
life [4]. Maternal metabolic, nutritional, and inflammatory factors have been suggested as mediators in the development of the various negative pregnancy outcomes associated with maternal obesity.

A higher body mass index (BMI) has been associated with an adverse nutritional status in both non-pregnant adults [5-7] and children [8,9]. An inverse relation between pre-pregnancy BMI and several micronutrients like folate, vitamin D, carotenoids, zinc, and essential fatty acids have been reported in pregnant women, and negative pregnancy outcomes related to obesity might be related to impaired micronutrient status [10-13]. An adequate B vitamin status during pregnancy is important for maternal health and normal fetal development [14]. Deficiencies of folate, cobalamin, riboflavin, or vitamin B6 are associated with an increased risk of placental abruption, still-births, low birth weight, preterm deliveries, preeclampsia, as well as fetal malformations [14].

Obesity in itself results in an inflammatory state in metabolic tissues [15], and higher levels of the inflammatory markers C-reactive protein, neopterin, and kynurenine/tryptophan ratio (KTR) are seen in overweight and obese adults [16,17]. Inflammation has been associated with low circulating levels of several micronutrients [18], such as the active form of vitamin $\mathrm{B}_{6}$, pyridoxal 5'-phosphate (PLP) [19], and vitamin D [20].

The objective of the study was to investigate whether BMI and inflammation are independent determinants of $B$ vitamin status, we investigated the association of pre-pregnancy BMI with plasma B vitamin status and inflammatory markers in pregnancy week 18 in 2797 women from the Norwegian Mother and Child Cohort Study (MoBa).

\section{Experimental Section}

\subsection{Study Population}

This study is based on a subsample of 2825 women included in the Norwegian Mother and Child Cohort Study (MoBa), a long-term, prospective study conducted by the Norwegian Institute of Public Health and including more than 100,000 Norwegian pregnant women and their infants during 1999-2008 [21]. The women included in this sub-study of MoBa gave a singleton birth between July 2002 and December 2003, and returned a baseline questionnaire including data on height and pre-pregnancy weight and donated a blood sample in pregnancy week 18 , and were registered in the Medical Birth Registry of Norway. A detailed description of this sub population and the sampling procedures has been published [22].

\subsection{Ethics}

Written informed consent was obtained from each participant, and the study was approved by the Regional Committee for Medical Research Ethics Sør-Øst A, 19/10-2011 (permission number 2009/2593a) and the Norwegian Data Inspectorate. All questions used in the MoBa can be found online at www.fhi.no/morogbarn.

\subsection{Blood Sampling and Laboratory Analyses}

Maternal non-fasting blood samples were collected in ethylenediamine tetraacetic acid (EDTA) tubes in median pregnancy week 18. The samples were centrifuged within $30 \mathrm{~min}$ after collection and stored at $4{ }^{\circ} \mathrm{C}$ until shipped overnight to the Norwegian Institute of Public Health in Oslo. On the day of receipt (usually within 1-2 days), plasma was aliquoted into polypropylene microtiter plates and stored at $-80^{\circ} \mathrm{C}$ until analyses.

Plasma folate was determined by a Lactobacillus casei microbiological assay [23] and plasma cobalamin (vitamin B12) by a Lactobacillus leichmannii microbiological assay [24]. Concurrent intake of antibiotics may interfere with microbiological assays and cause falsely reduced plasma levels of the vitamins [25], and samples with plasma folate levels $<2.33 \mathrm{nmol} / \mathrm{L}$ were excluded $(n=28$, i.e., the lower one percentile), leaving a total of 2797 samples to be included in the study. 
Plasma levels of total homocysteine (tHcy), a marker of folate and cobalamin status, and methylmalonic acid (MMA), a marker of cobalamin status, were assayed using a GC-MS method based on methylchloroformate derivatization [26]. Plasma levels of riboflavin (vitamin B2); pyridoxal 5'-phosphate (PLP; vitamin B6); the ratio between 3-hydroxykynurenine and xanthurenic acid (HK/XA), a marker of vitamin B6 status [27]; and two markers of interferon-gamma mediated cellular immune activation, neopterin [28] and KTR (Kynurenine/Tryptophan $\times 1000$ ) -the latter reflecting indoleamine-2,3-dioxygenase (IDO) activation [29]—-were analyzed using a liquid chromatography-tandem mass spectrometry assay [30]. All biomarkers were measured at the laboratory of Bevital AS (www.bevital.no).

\subsection{Covariates}

Data on maternal age at delivery, marital status, and parity were obtained from the Medical Birth Registry of Norway. Data on maternal education, smoking habits, pre-pregnancy BMI, weight increase to pregnancy week 18 , and use of supplements were obtained from the self-reported baseline cohort questionnaire. Pre-pregnancy BMI $\left(\mathrm{kg} / \mathrm{m}^{2}\right)$ was coded as $<18.5,18.5-24.9,25.0-29.9,30.0-34.9$, and $\geq 35.0$. Use of supplements was coded as non-user, use of folic acid or other supplement, and use of folic acid plus other supplement, based on reported intake from four weeks prior to conception up to pregnancy week 18. A B vitamin summary score was calculated as a sum of quintiles for folate, cobalamin, PLP, and riboflavin.

\subsection{Statistical Analyses}

Values are presented as means with standard deviation (SD) or medians with the interquartile range. Differences between groups were examined by ANOVA, Mann-Whitney U test and the Kruskal Wallis test. Differences in categorical variables were assessed with the Chi-square test. Multiple-linear regression models were used to assess the relation between pre-pregnancy BMI, use of supplements, parity, age, and inflammation with plasma B vitamin status obtained around pregnancy week 18. The odds ratio (ORs) for having a low B vitamin status (quintile 1) according to maternal factors, including the inflammation marker neopterin, was assessed by logistic regression.

To explore non-linearity, we modeled pre-pregnancy BMI versus B vitamins and metabolic markers, using one-dimensional smoothing splines in Generalized Additive Models (GAM), in a model adjusted for adjusted for use of supplements, maternal age, parity, and neopterin.

GAMs were computed using the package mgcv (version 1.4-1) in $\mathrm{R}$ (The R Foundation for Statistical Computing, version 2.8.1, Vienna, Austria) [31], and the SPSS/PASW statistical program version 22 (IBM Corp, Armonk, NY, USA).the company, the city, the country) was used for all other statistical analyses. Two-sided $p$-values $<0.05$ were considered statistically significant.

\section{Results}

\subsection{Characteristics of the Study Population According to Pre-Pregnancy BMI}

Demographic characteristics according to pre-pregnancy BMI are presented in Table 1. Fifty-eight percent of the women were multipara, and had a mean number of 1.5 (SD 0.7) former children, with no difference according to BMI group $(p=0.14)$. The majority of the women were healthy, a low percentage $(0.7 \%)$ had chronic hypertension and $2 \%$ had had IVF treatment. The use of multivitamin supplements differed according to BMI group, with an increasing trend for not using any supplements with higher BMI $(p<0.001)$. Regular use of alcohol was rare and $96 \%$ reported drinking alcohol never or less than once a month after becoming pregnant. A total of $231(8 \%)$ women reported daily smoking with a mean number of seven (SD five) cigarettes per day, with no significant difference in number between the smokers in the various BMI groups $(p=0.80)$. There was an inverse relation between pre-pregnancy BMI and weight gain to pregnancy week $18(r=-0.24, p<0.001)$ and to term $(r=-0.16$, $p<0.001)$. 
Table 1. Maternal characteristics according to maternal pre-pregnancy BMI, $n=2797$.

\begin{tabular}{|c|c|c|c|c|c|c|}
\hline & \multicolumn{5}{|c|}{ Pre-pregnancy BMI, Categories } & \multirow{3}{*}{$p$ Value } \\
\hline & $<18.5$ & $18.5-24.9$ & $25.0-29.9$ & $30.0-34.9$ & $\geq 35.0$ & \\
\hline & $n=80(3 \%)$ & $n=1827(65 \%)$ & $n=587(21 \%)$ & $n=213(8 \%)$ & $n=90(3 \%)$ & \\
\hline Primipara, $n(\%)$ & $47(59 \%)$ & $785(43 \%)$ & $231(39 \%)$ & $86(40 \%)$ & $26(29 \%)$ & $0.001^{\mathrm{b}}$ \\
\hline Age, years, mean (SD) & $27.8(4.9)$ & $29.9(4.5)$ & $29.9(4.6)$ & $29.8(4.6)$ & $29.5(4.8)$ & $0.003^{\mathrm{a}}$ \\
\hline \multicolumn{7}{|l|}{ Education } \\
\hline Primary school, $n(\%)$ & $9(12 \%)$ & $39(2 \%)$ & $15(3 \%)$ & $11(5 \%)$ & $6(7 \%)$ & \multirow{3}{*}{$<0.001^{b}$} \\
\hline Secondary school, $n(\%)$ & $30(41 \%)$ & $623(36 \%)$ & $273(48 \%)$ & $97(47 \%)$ & $48(55 \%)$ & \\
\hline University or college, $n(\%)$ & $35(47 \%)$ & $1077(62 \%)$ & $286(50 \%)$ & $98(48 \%)$ & $34(39 \%)$ & \\
\hline $\begin{array}{l}\text { Use of supplements anytime from four weeks } \\
\text { before pregnancy up to pregnancy week } 18\end{array}$ & $63(79 \%)$ & $1523(83 \%)$ & $470(79 \%)$ & $156(72 \%)$ & $61(68 \%)$ & $<0.001^{\mathrm{b}}$ \\
\hline Use of alcohol ( $\geq 1 /$ month), $n(\%)$ & $5(0.2 \%)$ & $83(3 \%)$ & $15(0.6 \%)$ & $1(0 \%)$ & $3(0.1 \%)$ & $0.009^{b}$ \\
\hline Daily smoking, $n(\%)$ & $13(16 \%)$ & $140(8 \%)$ & $47(8 \%)$ & $22(10 \%)$ & $9(10 \%)$ & $0.04^{\mathrm{b}}$ \\
\hline \multicolumn{7}{|l|}{$\begin{array}{l}\text { Weight increase, } \mathrm{kg} \text {, mean (SD), (\% of } \\
\text { pre-pregnancy weight) }\end{array}$} \\
\hline to pregnancy week 18 & $4.5(3.1)(9 \%)$ & $3.3(2.9)(5 \%)$ & $2.4(3.2)(3 \%)$ & $1.1(3.5)(1 \%)$ & $-0.1(4.3)(-0.1 \%)$ & $<0.001^{\mathrm{a}}<0.001^{\mathrm{a}}$ \\
\hline to birth & $17.3(6.3)(35 \%)$ & $15.5(5.9)(25 \%)$ & $14.8(6.7)(20 \%)$ & $11.5(7.3)(13 \%)$ & $8.7(8.9)(8 \%)$ & $<0.001^{\mathrm{a}}<0.001^{\mathrm{a}}$ \\
\hline Birth weight, $g$, mean (SD) & $3343(635)$ & $3575(588)$ & $3727(600)$ & $3696(648)$ & $3758(755)$ & $<0.001^{\mathrm{a}}$ \\
\hline
\end{tabular}


Women in the highest pre-pregnancy BMI group (BMI $\geq 35)$ put on less weight during pregnancy, they were more likely to be multipara, not use micronutrient supplements, and to have a lower educational level $(p<0.01)$. The lowest mean birth weight was seen in women with a pre-pregnancy BMI <18.5 (Table 1).

\subsection{Plasma B Vitamin Status According to Pre-Pregnancy BMI}

There was a trend towards lower levels of B vitamins and higher levels of the metabolic markers with higher pre-pregnancy BMI (Table 2, Figure 1). The best B vitamin status was seen in women with a normal pre-pregnancy BMI (18.5-24.9), as they had the highest levels of folate, PLP, and riboflavin with the lowest $\mathrm{tHcy}$ and HK/XA ratio (Table 2). Cobalamin decreased with increasing BMI, but this was not reflected in the MMA levels, which were inversely related to pre-pregnancy BMI.

The circulating B-vitamins were inversely related to their functional markers, as expected. tHcy was inversely related to folate $(r=-0.48, p<0.001)$, less to cobalamin $(r=-0.24, p<0.001)$, PLP $(r=-0.16, p<0.001)$, and riboflavin $(r=-0.15, p<0.001)$. MMA was inversely related to cobalamin $(r=-0.17, p<0.001)$ and HK/XA to PLP $(r=-0.29, p<0.001)$. All B vitamins were positively related to each other $(r>0.12, p<0.001)$.
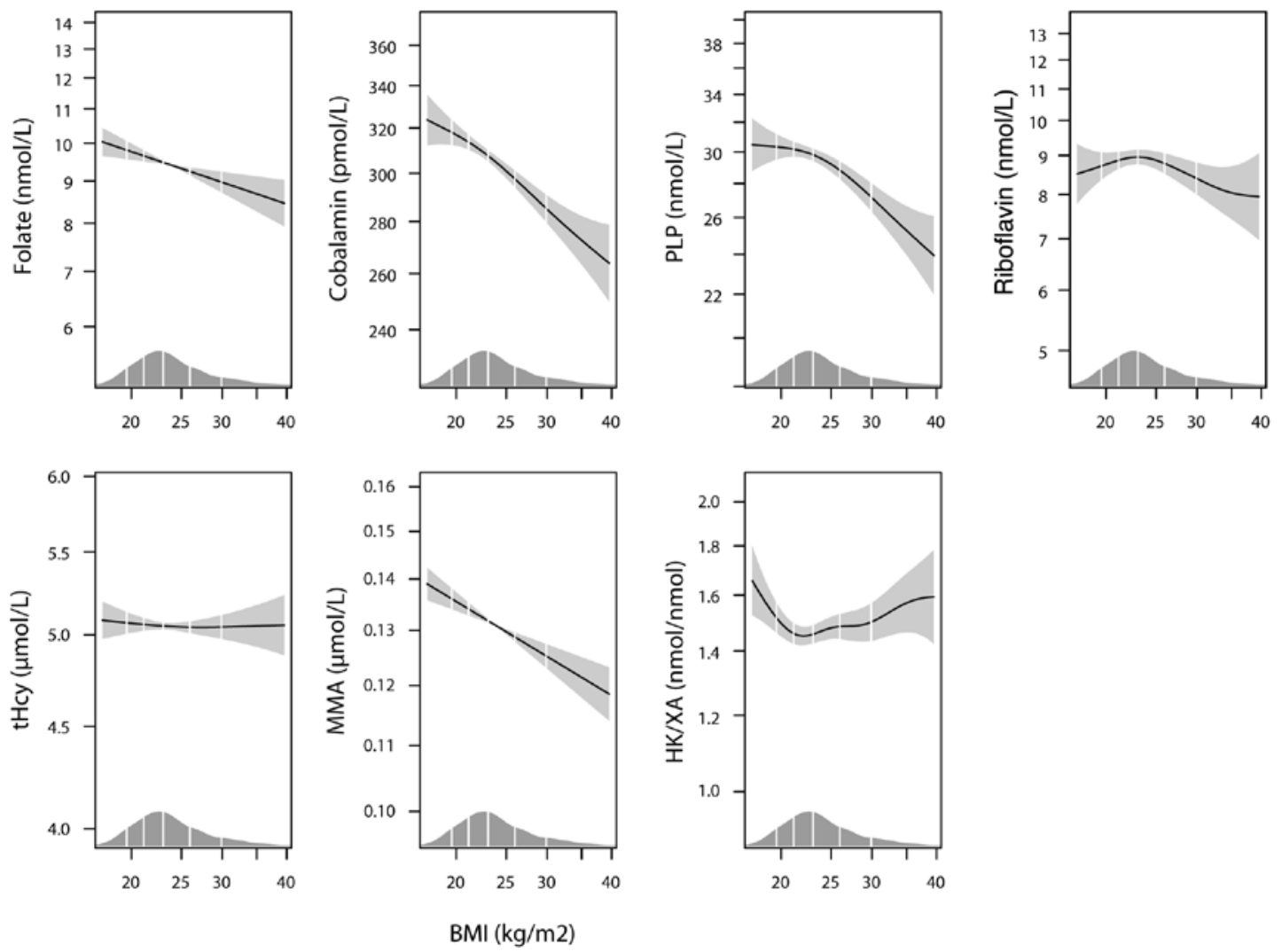

Figure 1. The association of pre-pregnancy BMI with cobalamin, folate, PLP, riboflavin, tHcy, MMA, and HK/XA by generalized additive models (GAM), adjusted for use of multisupplements, maternal age, parity, and neopterin. The solid line shows the fitted model and the shaded areas indicate $95 \%$ CIs. PLP, pyridoxal 5'phosphate; tHcy, total homocysteine; MMA, methylmalonic acid, HK/XA, 3-hydroxykynurenine/xanthurenic acid ratio. 
Table 2. Maternal plasma levels of vitamins, metabolic and inflammation markers in pregnancy week 18 according to pre-pregnancy BMI, $n=2797$.

\begin{tabular}{|c|c|c|c|c|c|c|}
\hline & \multicolumn{5}{|c|}{ Pre-pregnancy BMI; Categories } & \multirow{3}{*}{$p$ Value } \\
\hline & $<18.5$ & $18.5-24.9$ & $25.0-29.9$ & $30.0-34.9$ & $\geq 35.0$ & \\
\hline & $n=80$ & $n=1827$ & $n=587$ & $n=213$ & $n=90$ & \\
\hline Plasma folate, $\mathrm{nmol} / \mathrm{L}^{\mathrm{a}}$ & $8.8(6.0-15.7)$ & $9.2(6.3-16.0)$ & $8.1(5.7-12.8)$ & $7.3(5.1-12.2)$ & $7.3(5.0-12.1)$ & $<0.001$ \\
\hline Plasma cobalamin, $\mathrm{pmol} / \mathrm{L}^{\mathrm{a}}$ & $328(243-383)$ & $314(254-386)$ & $301(240-363)$ & $271(220-338)$ & $268(204-317)$ & $<0.001$ \\
\hline Plasma PLP, nmol/ $\mathrm{L}^{\mathrm{a}}$ & $27.0(21.4-39.7)$ & $28.3(21.8-40.7)$ & $26.6(20.6-35.6)$ & $23.8(17.4-33.7)$ & $21.5(17.0-30.1)$ & $<0.001$ \\
\hline Plasma riboflavin, $\mathrm{nmol} / \mathrm{L}^{\mathrm{a}}$ & $7.8(4.8-14.4)$ & $8.1(5.6-13.2)$ & $7.8(5.2-13.9)$ & $7.2(5.2-11.0)$ & $6.9(4.4-10.1)$ & 0.004 \\
\hline B vitamin status $a, b$ & $12.2(3.7)$ & $12.5(3.6)$ & $11.7(3.7)$ & $10.6(3.7)$ & $10.1(3.4)$ & $<0.001$ \\
\hline Plasma tHcy, $\mu \mathrm{mol} / \mathrm{L}^{\mathrm{a}}$ & $5.00(4.22-5.92)$ & $4.91(4.27-5.79)$ & $4.94(4.23-5.78)$ & $5.04(4.44-6.21)$ & $5.33(4.43-6.13)$ & 0.03 \\
\hline Plasma MMA, $\mu \mathrm{mol} / \mathrm{L}^{\mathrm{a}}$ & $0.13(0.11-0.16)$ & $0.13(0.11-0.16)$ & $0.13(0.10-0.16)$ & $0.12(0.10-0.15)$ & $0.12(0.10-0.15)$ & 0.009 \\
\hline Plasma HK/XA a & $1.6(1.2-2.1)$ & $1.4(1.0-2.0)$ & $1.5(1.1-2.1)$ & $1.7(1.2-2.2)$ & $1.8(1.2-2.4)$ & $<0.001$ \\
\hline Plasma neopterine, $\mu \mathrm{mol} / \mathrm{L}^{\mathrm{a}}$ & $6.7(6.1-8.1)$ & $7.0(6.1-8.1)$ & $7.3(6.3-8.6)$ & $7.9(7.0-9.1)$ & $8.5(7.31-9.9)$ & $<0.001$ \\
\hline $\mathrm{KTR}, \mathrm{nmol} / \mu \mathrm{mol}^{\mathrm{a}}$ & $18.1(16.0-21.5)$ & $18.3(16.2-20.6)$ & $18.8(16.8-21.2)$ & $19.6(17.5-22.8)$ & $21.2(18.5-24.0)$ & $<0.001$ \\
\hline
\end{tabular}

a Median (IOR), by Kruskal Wallis test; ${ }^{b}$ B vitamin status; summary score based on added quintiles of the 4 B vitamins, Mean (SD), by ANOVA; tHcy, total homocysteine; MMA, methylmalonic acid; HK/XA: 3-hydroxykynurenine/xanthurenic acid; KTR, kynurenine/tryptophan ratio. 


\subsection{Inflammation Markers According to Pre-Pregnancy BMI}

There was a positive correlation between pre-pregnancy BMI and the inflammation markers neopterin $(r=0.18, p<0.001)$ and KTR $(r=0.13, p<0.001)$, as demonstrated in Figure 2. Neopterin and KTR were strongly correlated to each other $(r=0.48, p<0.001)$.
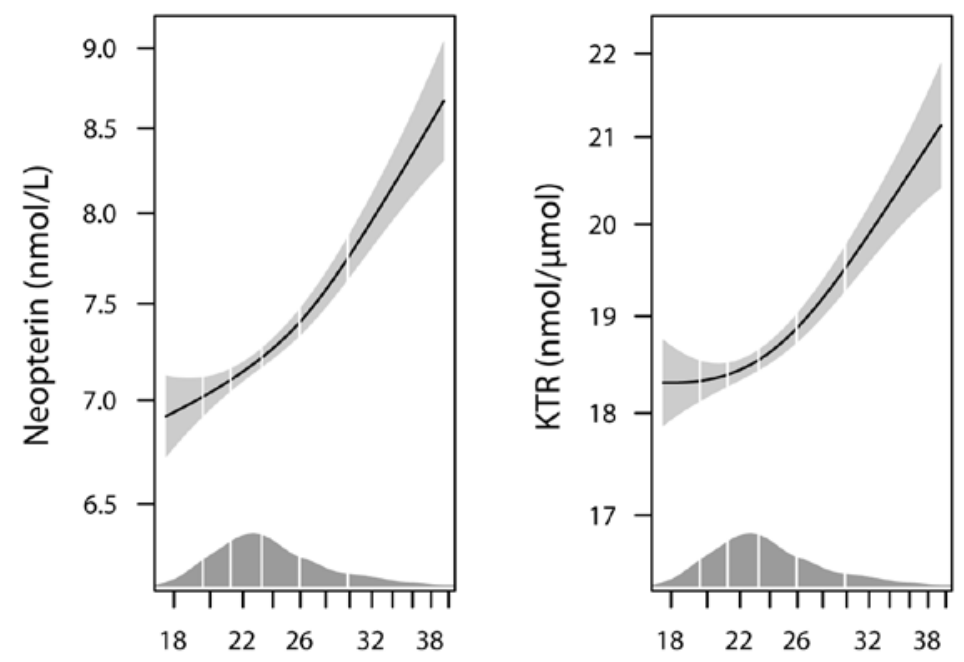

$\mathrm{BMI}(\mathrm{kg} / \mathrm{m} 2)$

Figure 2. The association of pre-pregnancy BMI with neopterin and KTR by Generalized additive models (GAM), adjusted for use of multisupplements, maternal age, and parity. The solid line shows the fitted model and the shaded areas indicate 95\% CIs. KTR, kynurenine/tryptophan ratio.

\subsection{Maternal Factors and Inflammation Markers as Determinants of Plasma B Vitamin Status in Pregnancy} Week 18

Use of supplements was the most consistent and strongest determinant for maternal $B$ vitamin status, with significant influence on folate, cobalamin, PLP, riboflavin, tHcy, and HK/XA, in a multiple linear regression model, which additionally included pre-pregnancy BMI, age, parity, and neopterin (Table 3). In this model, pre-pregnancy BMI was a significant determinant of all vitamin markers except for riboflavin and tHcy, whereas parity was strongly negatively correlated to folate and PLP status. All parameters in the model were significantly correlated to the calculated B vitamin summary score (Table 3). Neopterin was significantly negative related to PLP, and positively to the metabolic markers tHcy, MMA, and HK/XA. Substituting neopterin with KTR in the model did not essentially change the results (data not shown). Including gestational weight gain in pregnancy week 18 as an additional factor did not change the results.

The OR for having a low calculated B vitamin summary score (quintile 1) was increased with pre-pregnancy BMI $>30.0$ and higher parity, and reduced with higher maternal age and use of supplements in a logistic regression model, which additionally included neopterin quartiles (Table 4). A high pre-pregnancy BMI was a predictor of low cobalamin and PLP levels, multiparity was a predictor of low folate levels, higher maternal age was associated with better folate and riboflavin status, whereas use of supplements was associated with better status of all four B vitamins. Increased inflammation, evaluated by higher neopterin levels, was only a predictor of low PLP in this model. Substituting neopterin with KTR in the model did not essentially change the results. 
Table 3. Determinants of maternal plasma B vitamin status in pregnancy week 18 by multiple linear regression, $n=2797$.

\begin{tabular}{|c|c|c|c|c|c|c|c|c|}
\hline & $\begin{array}{c}\text { Plasma } \\
\text { Folate, } \\
\text { nmol/L }\end{array}$ & $\begin{array}{c}\text { Plasma } \\
\text { Cobalamin, } \\
\text { pmol/L }\end{array}$ & $\begin{array}{c}\text { Plasma PLP, } \\
\text { nmol/L }\end{array}$ & $\begin{array}{c}\text { Plasma } \\
\text { Riboflavin, } \\
\text { nmol/L }\end{array}$ & $\begin{array}{c}\text { Plasma tHcy, } \\
\mu \mathrm{mol} / \mathrm{L}\end{array}$ & $\begin{array}{c}\text { Plasma MMA, } \\
\mu \mathrm{mol} / \mathrm{L}\end{array}$ & $\begin{array}{l}\text { Plasma } \\
\text { HK/XA }\end{array}$ & $\begin{array}{l}\text { B Vitamin } \\
\text { Score }^{a}\end{array}$ \\
\hline & B $(95 \%$ CI $)$ & B $(95 \%$ CI $)$ & B $(95 \%$ CI $)$ & B (95\% CI) & B $(95 \%$ CI $)$ & B $(95 \%$ CI $)$ & B $(95 \%$ CI $)$ & B $(95 \%$ CI $)$ \\
\hline Pre-pregnancy BMI ${ }^{\mathrm{c}}$ & $\begin{array}{c}-0.59 * * \\
(-0.98,-0.20)\end{array}$ & $\begin{array}{c}-16.7^{* *} \\
(-22.0,-11.4)\end{array}$ & $\begin{array}{c}-2.55^{* *} \\
(-3.72,-1.38)\end{array}$ & $\begin{array}{c}-0.60 \\
(-1.25,0.06)\end{array}$ & $\begin{array}{c}-0.02 \\
(-0.16,0.12)\end{array}$ & $\begin{array}{c}-0.006^{* *} \\
(-0.008,-0.003)\end{array}$ & $\begin{array}{c}0.11 * \\
(0.04,0.18)\end{array}$ & $\begin{array}{c}-0.47^{* *} \\
(-0.60,-0.35)\end{array}$ \\
\hline Parity ${ }^{\mathrm{e}}$ & $\begin{array}{c}-1.33^{* *} \\
(-1.72,-0.95)\end{array}$ & $\begin{array}{c}-3.6 \\
(-8.8,1.6)\end{array}$ & $\begin{array}{c}-1.28 \\
(-2.43,-0.12)\end{array}$ & $\begin{array}{c}-1.08 * \\
(-1.73,-0.43)\end{array}$ & $\begin{array}{c}-0.01 \\
(-0.15,0.13)\end{array}$ & $\begin{array}{c}-0.001 \\
(-0.004,0.002)\end{array}$ & $\begin{array}{c}-0.03 \\
(-0.09,0.04)\end{array}$ & $\begin{array}{c}-0.34 \\
(-0.47,-0.22)\end{array}$ \\
\hline Age $^{d}$ & $\begin{array}{c}2.69 * * \\
(2.05,3.32)\end{array}$ & $\begin{array}{c}12.3 * \\
(3.6,20.9)\end{array}$ & $\begin{array}{c}1.96^{*} \\
(0.06,3.86)\end{array}$ & $\begin{array}{c}0.30 \\
(-0.77,1.36)\end{array}$ & $\begin{array}{c}0.04 \\
(-0.19,0.27)\end{array}$ & $\begin{array}{c}0.002 \\
(-0.002,0.007)\end{array}$ & $\begin{array}{c}-0.12 * \\
(-0.24,-0.01)\end{array}$ & $\begin{array}{c}0.63 \text { ** } \\
(0.43,0.83)\end{array}$ \\
\hline Use of supplements ${ }^{b}$ & $\begin{array}{c}5.14 \\
(4.35,5.94)\end{array}$ & $\begin{array}{c}13.0^{*} \\
(2.3,23.7)\end{array}$ & $\begin{array}{c}8.49^{* *} \\
(6.12,10.85)\end{array}$ & $\begin{array}{c}1.80 * \\
(0.48,3.13)\end{array}$ & $\begin{array}{c}-0.75 * * \\
(-1.03,-0.47)\end{array}$ & $\begin{array}{c}0.001 \\
(-0.004,0.007)\end{array}$ & $\begin{array}{c}-0.21 \text { * } \\
(-0.35,-0.07)\end{array}$ & $\begin{array}{c}1.73^{* *} \\
(1.48,1.98)\end{array}$ \\
\hline Neopterin ${ }^{\mathrm{f}}$ & $\begin{array}{c}-0.12 \\
(-0.35,0.11)\end{array}$ & $\begin{array}{c}-1.9 \\
(-5.0,1.2)\end{array}$ & $\begin{array}{c}-1.00 * \\
(-1.68,-0.31)\end{array}$ & $\begin{array}{c}-0.08 \\
(-0.47,0.30)\end{array}$ & $\begin{array}{c}0.10 * \\
(0.02,0.18)\end{array}$ & $\begin{array}{c}0.003 \text { ** } \\
(0.001,0.004)\end{array}$ & $\begin{array}{c}0.19^{* *} \\
(0.15,0.23)\end{array}$ & $\begin{array}{c}-0.12 * * \\
(-0.20,-0.05)\end{array}$ \\
\hline
\end{tabular}

All variables were included in the model; ${ }^{a} \mathrm{~B}$ vitamin score; added quintiles of folate, cobalamin, PLP and riboflavin; ${ }^{\mathrm{b}}$ No use versus use of supplements any time from four weeks before pregnancy up to pregnancy week $18{ }^{\text {c }}$ Pre-pregnancy BMI, categorized; $<18.5,18.5-24.9,25.0-29.9,30.0-34.9, \geq 35.0$; ${ }^{\mathrm{d}}$ Age, categorized; $<25$ years, $25-35$ years, $>35$ years; ${ }^{\text {e }}$ Parity, categorized; $0,1,2,3+;{ }^{\mathrm{f}}$ Neopterin, quintiles; $\leq 5.84,5.85-6.68,6.69-7.50,7.51-8.67, \geq 8.68 ; * p$ value $<0.05 ;{ }^{* *} p$ value $<0.001$. CI: indicates confidence interval. 
Table 4. OR for low B vitamin status according to maternal factors, by logistic regression $(n=2797)$.

\begin{tabular}{|c|c|c|c|c|c|}
\hline \multirow[b]{2}{*}{ Independent Variables } & \multicolumn{5}{|c|}{ OR $(95 \% \mathrm{CI})$ for } \\
\hline & $\begin{array}{l}\text { Plasma Folate } \\
<5.45 \mathrm{nmol} / \mathrm{L} \\
\text { (Quintile 1) }\end{array}$ & $\begin{array}{l}\text { Plasma Cobalamin } \\
<230 \mathrm{pmol} / \mathrm{L} \\
\text { (Quintile 1) }\end{array}$ & $\begin{array}{c}\text { Plasma PLP } \\
<19.26 \mu \mathrm{mol} / \mathrm{L} \\
\text { (Quintile 1) }\end{array}$ & $\begin{array}{c}\text { Plasma Riboflavin } \\
<4.91 \mu \mathrm{mol} / \mathrm{L} \\
\text { (Quintile 1) }\end{array}$ & $\begin{array}{l}\text { B Vitamin Score a } \\
\text { (Quintile 1) }\end{array}$ \\
\hline \multicolumn{6}{|c|}{ Pre-pregnancy BMI (vs. category 2 18.5-24.9) } \\
\hline$<18.5$ & $1.0(0.5-1.8)$ & $1.1(0.6-1.9)$ & $1.0(0.5-1.8)$ & $1.7(1.0-2.8)$ & $1.1(0.7-1.9)$ \\
\hline $25.0-29.9$ & $1.1(0.9-1.5)$ & $1.3(1.0-1.6)$ & $1.3(1.0-1.6)$ & $1.3(1.0-1.7)$ & $1.5(1.2-1.8)$ \\
\hline $30.0-34.9$ & $1.5(1.0-2.1)$ & $2.1(1.5-2.9)$ & $2.1(1.6-3.0)$ & $1.4(1.0-2.0)$ & $2.7(2.0-3.7)$ \\
\hline$\geq 35.0$ & $1.7(1.0-2.8)$ & $2.3(1.4-3.6)$ & $2.2(1.4-3.5)$ & $1.8(1.1-3.0)$ & $2.8(1.7-4.3)$ \\
\hline$p$ trend & 0.006 & $<0.001$ & $<0.001$ & 0.001 & $<0.001$ \\
\hline \multicolumn{6}{|l|}{ Parity (vs. primipara) } \\
\hline Para 1 & $1.2(1.0-1.6)$ & $1.1(0.9-1.4)$ & $1.3(1.0-1.6)$ & $1.3(1.0-1.6)$ & $1.3(1.0-1.6)$ \\
\hline Para 2 & $1.7(1.2-2.3)$ & $1.3(1.0-1.7)$ & $1.1(0.8-1.5)$ & $1.2(0.9-1.6)$ & $1.6(1.2-2.1)$ \\
\hline Para 3+ & $3.2(2.1-4.9)$ & $1.6(1.0-2.4)$ & $1.1(0.7-1.8)$ & $1.4(0.9-2.2)$ & $2.1(1.4-3.1)$ \\
\hline$p$ trend & $<0.001$ & 0.02 & 0.36 & 0.11 & $<0.001$ \\
\hline \multicolumn{6}{|l|}{ Maternal age (vs. $\leq 25$ years) } \\
\hline $25-35$ & $0.4(0.3-0.6)$ & $0.7(0.6-1.0)$ & $0.7(0.7-1.0)$ & $0.7(0.6-1.0)$ & $0.5(0.4-0.7)$ \\
\hline$\geq 35$ & $0.3(0.2-0.5)$ & $0.8(0.5-1.2)$ & $0.8(0.5-1.1)$ & $0.6(0.4-0.9)$ & $0.4(0.3-0.6)$ \\
\hline$p$ trend & $<0.001$ & 0.11 & 0.11 & 0.004 & $<0.001$ \\
\hline \multicolumn{6}{|c|}{ Use of supplements (vs. non-user) } \\
\hline User & $0.2(0.2-0.2)$ & $0.8(0.6-1.0)$ & $0.5(0.4-0.6)$ & $0.6(0.5-0.8)$ & $0.3(0.3-0.4)$ \\
\hline$p$ trend & $<0.001$ & 0.03 & $<0.001$ & $<0.001$ & $<0.001$ \\
\hline \multicolumn{6}{|c|}{ Neopterin (vs. $\leq 6.20 \mu \mathrm{mol} / \mathrm{L}$, Quartile 1) } \\
\hline $6.21-7.17$ & $1.1(0.8-1.4)$ & $1.1(0.8-1.5)$ & $1.1(0.8-1.5)$ & $0.9(0.7-1.2)$ & $1.0(0.8-1.3)$ \\
\hline $7.18-8.40$ & $1.3(1.0-1.8)$ & $1.0(0.8-1.4)$ & $1.1(0.8-1.4)$ & $0.9(0.7-1.1)$ & $1.1(0.9-1.4)$ \\
\hline$\geq 8.41$ & $1.2(0.9-1.6)$ & $1.2(0.9-1.6)$ & $1.7(1.3-2.2)$ & $0.9(0.7-1.2)$ & $1.2(1.0-1.6)$ \\
\hline$p$ trend & 0.11 & 0.24 & $<0.001$ & 0.38 & 0.05 \\
\hline
\end{tabular}

All variables were included in the model; ${ }^{\text {B }}$ vitamin score; added quintiles of folate, cobalamin, PLP and riboflavin. OR: Odds ratio. 
The relations between pre-pregnancy BMI and B vitamins and metabolic markers, visualized by GAM in a model which additionally corrected for use of supplements, maternal age, parity, and neopterin, are shown in Figure 1. The association curves for folate, cobalamin, PLP, and MMA show a linear negative relation to pre-pregnancy BMI, while the relation between pre-pregnancy BMI and the other biomarkers are inverse U-shaped (riboflavin), null (tHcy), or inverse in the lower range (HK/XA).

The association curves between pre-pregnancy BMI and the inflammation markers, neopterin and KTR, visualized by GAM in a model which also corrected for use of supplements, maternal age, and parity, show a strong linear relation through the whole range of BMI values (Figure 2).

\section{Discussion}

\subsection{Main Findings}

In this study of healthy women in pregnancy week 18 , use of multi supplements was the strongest maternal determinant for B vitamin status. Pre-pregnancy BMI was inversely related to folate, cobalamin, PLP, and riboflavin levels, and associated with increased markers of cellular immune activation. Inflammation seemed to be an independent predictor of low PLP levels.

\subsection{Strength and Limitations}

All pregnant women in Norway were invited to participate in the MoBa study, but the attendance rate was only $38.5 \%$, rendering the cohort not representative of the Norwegian population of pregnant women. The women who participated in the MoBa study are reported to be older, more frequently vitamin users, non-smokers, and primiparous [32]. Pre-pregnancy weight was self-reported around pregnancy week 18, and as obesity is an important determinant of underreporting BMI [33], self-reporting without verification is a limitation of the study.

The samples were stored at $-80^{\circ} \mathrm{C}$ before analyzing. The stability of plasma metabolites according to sample handling and storage conditions has been validated and the biomarkers investigated do not change significantly during storage at $-80^{\circ} \mathrm{C}$ [34].

C-reactive protein, CRP, an acute phase reactant and a commonly used inflammation marker, might have added additional information about low grade inflammation, but was not analyzed, which is a limitation of the study.

\subsection{Interpretation}

\subsubsection{Effects of Pre-Pregnancy BMI on Gestational Weight Gain and Birth Weight}

In a former study of the MoBa cohort including approximately 58,000 mothers, the majority (65\%) reported a normal pre-pregnancy BMI (18.5-24.9), whereas 2.9\% were underweight $(<18.5)$, and $2.6 \%$ were obese $(\geq 35)$ [35], which is in accordance with the findings in the present substudy.

We observed a significant inverse relation between pre-pregnancy BMI and gestational weight gain up to pregnancy week 18 and throughout pregnancy, and despite this, a higher pre-pregnancy BMI was associated with a higher birth weight, which has been reported previously [35].

\subsubsection{Pregnancy Related Changes in Biochemical Parameters}

Physiological changes in pregnancy, including hemodilution, altered renal function, hormonal status, and binding-protein concentrations, affect plasma B vitamin levels and the relation to their functional metabolic markers [36,37]. Folate, cobalamin, and PLP tend to decrease, whereas riboflavin is reported to show only minor changes during pregnancy [38-42]. tHcy, a marker of folate and cobalamin deficiency [43], is 30\%-60\% lower in pregnant compared to nonpregnant women, with the lowest levels seen in the second trimester [44]. MMA, a marker of cobalamin deficiency [45], is reported to be reduced during the first two trimesters, thereafter gradually increasing [46]. We observed a strong 
inverse relation between folate and tHcy, and a weaker relation between cobalamin and MMA, as observed by others $[36,47,48]$.

The ratio HK/XA has been shown to have a strong negative correlation with plasma levels of PLP, the active form of vitamin $B 6$, and has been proposed as a potential markers of functional vitamin B6 status [27]. The inverse relation between PLP and HK/XA has not been previously documented in pregnant women, but we observed lower PLP and higher HK/XA ratios with increasing pre-pregnancy BMI, indicating a functional vitamin B6 deficiency, particularly in women with a pre-pregnancy $\mathrm{BMI} \geq 30$.

Extensive changes in the maternal immune system are necessary for maintaining a normal pregnancy [49] and both neopterin levels and KTR are reported to increase during pregnancy [50] Neopterin levels correlate with gestational age $(r=0.28, p=0.001)$ and are reported to be higher in pregnancies complicated with preterm birth and preeclampsia [51-53].

\subsubsection{Maternal Predictors for B Vitamin Status}

An inverse relation between pre-pregnancy BMI and folate, vitamin D, carotenoids has formerly been reported $[10,11,13]$. Our results have expanded this knowledge by reporting also lower levels of PLP (vitamin B6), riboflavin (vitamin B2), and cobalamin (vitamin B12) with higher pre-pregnancy BMI.

Pre-pregnancy BMI, use of multisupplements, parity, and maternal age were all related to $B$ vitamin status. We observed a slightly U-shaped relation between pre-pregnancy BMI and B vitamin levels in pregnancy week 18 , with the best status seen in women with a normal pre-pregnancy BMI (18.5-24.9), slightly lower in underweight women (BMI < 18.5) and lowest in obese women (BMI $\geq 35.0$ ). The strongest maternal determinant for B vitamin status was use of multisupplements, and the percentage of users was higher in normal weight compared to obese women, which might explain the inverse relation between pre-pregnancy BMI and vitamin status. Use of micronutrient supplements during pregnancy has been associated with better socioeconomic status [48], known to be related to a better diet, maternal health, and pregnancy outcome [54]. Multiparity ( $\geq 3)$ was associated with an increased risk of folate deficiency, while maternal age $>25$ years was associated with a better folate status. In the MoBa cohort, the $10 \%$ who had used supplements regularly from one month before pregnancy throughout the first trimester (as recommended) were more likely to be older, married, nonsmokers, with a higher income and lower parity [54]. Compared to women with a lower pre-pregnancy BMI, obese women $(B M I \geq 35)$ had not increased their weight in pregnancy week 18 , when the blood samples were collected, which might contribute to their lower micronutrient status.

\subsubsection{The Complex Relation between Pre-pregnancy BMI, Inflammation, and Vitamin Levels}

We observed a linear relation between pre-pregnancy BMI and the markers of cellular immune activation, neopterin and KTR, as previously reported in non-pregnant adults [16]. Inflammation is reported to be associated with lower plasma levels of several micronutrients, particularly vitamin B6 and vitamin D [18-20], but the magnitude of effect varies between different micronutrients and individuals $[18,55,56]$. The lower PLP levels associated with inflammation have been proposed to be due to increased PLP degradation [57] and to PLP redistribution from plasma to tissues [58], and PLP have been suggested to reflect interferon- $\gamma$-mediated immune activation [59].

In this study, neopterin was inversely related to PLP and positively to HK/XA, but not to any other vitamin, in both multiple linear and logistic regression models, which included pre-pregnancy BMI and other maternal factors. The increase in the functional marker, HK/XA, suggests that low PLP does not merely refelect altered distribution, but that inflammation may be an independent risk factor for lower vitamin B6 status.

\section{Conclusions}

A high pre-pregnancy BMI is associated with lower levels of folate, cobalamin, PLP, and riboflavin; and increased levels of the cellular inflammation markers, neopterin, and KTR. As an optimal 
micronutrient status is vital for normal fetal development, the observed lower B vitamin levels may contribute to the negative pregnancy outcomes associated with maternal obesity. Assessment of $B$ vitamin status should be encouraged in women with a high pre-pregnancy BMI when planning a pregnancy.

Acknowledgments: We are grateful to all the families in Norway who took part in this cohort study. The Norwegian Mother and Child Cohort Study is supported by the Norwegian Ministry of Health and the Ministry of Education and Research, NIH/NIEHS (contract no. NO-ES-75558), NIH/NINDS (grant no.1 UO1 NS 047537-01), and the Norwegian Research Council/FUGE (grant no. 151918/S10).

Author Contributions: (1) Designed research: A.-L.B.-M., P.M.U., P.M., C.S., and S.E.V.; (2) Conducted research: C.R., P.M., and C.S.; (3) Analyzed data: A.-L.B.-M., A.U., R.M.N., and Ø.M.; (4) Wrote the paper: A.-L.B.-M., and P.M.U.; (5) Primary responsibility for final content: A.-L.B.-M.; (5) Primary responsibility for final content: A.-L.B.-M.; (6) All authors have read and approved the final version of the manuscript: A.-L.B.-M., A.U., Ø.M., R.M.N., C.R., P.M., C.S., S.E.V., T.R.-K., and P.M.U.

Conflicts of Interest: The authors declare no conflict of interest.

\section{Abbreviations}

MoBa: the Norwegian Mother and Child Cohort; tHcy: total homocysteine; MMA: methylmalonic acid; HK: 3-hydroxykynurenine; XA: xanthurenic acid; PLP: pyridoxal 5'-phosphate; KTR: kynurenine/tryptophan ratio; IDO: indoleamine-2,3-dioxygenase.

\section{References}

1. Swinburn, B.A.; Sacks, G.; Hall, K.D.; McPherson, K.; Finegood, D.T.; Moodie, M.L.; Gortmaker, S.L. The global obesity pandemic: Shaped by global drivers and local environments. Lancet 2011, 378, 804-814. [CrossRef]

2. Catalano, P.M.; Ehrenberg, H.M. The short- and long-term implications of maternal obesity on the mother and her offspring. Br. J. Obstet. Gynaecol. 2006, 113, 1126-1133. [CrossRef] [PubMed]

3. Stothard, K.J.; Tennant, P.W.; Bell, R.; Rankin, J. Maternal overweight and obesity and the risk of congenital anomalies: A systematic review and meta-analysis. J. Am. Med. Assoc. 2009, 301, 636-650. [CrossRef] [PubMed]

4. Boney, C.M.; Verma, A.; Tucker, R.; Vohr, B.R. Metabolic syndrome in childhood: Association with birth weight, maternal obesity, and gestational diabetes mellitus. Pediatrics 2005, 115, e290-e296. [CrossRef] [PubMed]

5. Kimmons, J.E.; Blanck, H.M.; Tohill, B.C.; Zhang, J.; Khan, L.K. Associations between body mass index and the prevalence of low micronutrient levels among US adults. MedGenMed 2006, 8, 59. [PubMed]

6. Mojtabai, R. Body mass index and serum folate in childbearing age women. Eur. J. Epidemiol. 2004, 19, 1029-1036. [CrossRef] [PubMed]

7. Samuel, L.; Borrell, L.N. The effect of body mass index on optimal vitamin D status in U.S. adults: The National Health and Nutrition Examination Survey 2001-2006. Ann. Epidemiol. 2013, 23, 409-414. [CrossRef] [PubMed]

8. Nead, K.G.; Halterman, J.S.; Kaczorowski, J.M.; Auinger, P.; Weitzman, M. Overweight children and adolescents: A risk group for iron deficiency. Pediatrics 2004, 114, 104-108. [CrossRef] [PubMed]

9. Strauss, R.S. Comparison of serum concentrations of alpha-tocopherol and beta-carotene in a cross-sectional sample of obese and nonobese children (NHANES III). National Health and Nutrition Examination Survey. J. Pediatr. 1999, 134, 160-165. [CrossRef]

10. Bodnar, L.M.; Catov, J.M.; Roberts, J.M.; Simhan, H.N. Pre-pregnancy obesity predicts poor vitamin D status in mothers and their neonates. J. Nutr. 2007, 137, 2437-2442. [PubMed]

11. Kim, H.; Hwang, J.Y.; Kim, K.N.; Ha, E.H.; Park, H.; Ha, M.; Lee, K.Y.; Hong, Y.C.; Tamura, T.; Chang, N. Relationship between body-mass index and serum folate concentrations in pregnant women. Eur. J. Clin. Nutr. 2012, 66, 136-138. [CrossRef] [PubMed]

12. Tamura, T.; Goldenberg, R.L.; Johnston, K.E.; Chapman, V.R. Relationship between pre-pregnancy BMI and plasma zinc concentrations in early pregnancy. Br. J. Nutr. 2004, 91, 773-777. [CrossRef] [PubMed] 
13. Tomedi, L.E.; Chang, C.C.; Newby, P.K.; Evans, R.W.; Luther, J.F.; Wisner, K.L.; Bodnar, L.M. Pre-pregnancy obesity and maternal nutritional biomarker status during pregnancy: A factor analysis. Public Health Nutr. 2013, 16, 1414-1418. [CrossRef] [PubMed]

14. Allen, L.H. Multiple micronutrients in pregnancy and lactation: An overview. Am. J. Clin. Nutr. 2005, 81, 1206S-1212S. [PubMed]

15. Gregor, M.F.; Hotamisligil, G.S. Inflammatory mechanisms in obesity. Ann. Rev. Immunol. 2011, $29,415-445$. [CrossRef] [PubMed]

16. Theofylaktopoulou, D.; Midttun, O.; Ulvik, A.; Ueland, P.M.; Tell, G.S.; Vollset, S.E.; Nygård, O.; Eussen, S.J. A community-based study on determinants of circulating markers of cellular immune activation and kynurenines: The Hordaland Health Study. Clin. Exp. Immunol. 2013, 173, 121-130. [CrossRef] [PubMed]

17. Visser, M.; Bouter, L.M.; McQuillan, G.M.; Wener, M.H.; Harris, T.B. Elevated C-reactive protein levels in overweight and obese adults. J. Am. Med. Assoc. 1999, 282, 2131-2135. [CrossRef]

18. Duncan, A.; Talwar, D.; McMillan, D.C.; Stefanowicz, F.; O’Reilly, D.S. Quantitative data on the magnitude of the systemic inflammatory response and its effect on micronutrient status based on plasma measurements. Am. J. Clin. Nutr. 2012, 95, 64-71. [CrossRef] [PubMed]

19. Gori, A.M.; Sofi, F.; Corsi, A.M.; Gazzini, A.; Sestini, I.; Lauretani, F.; Bandinelli, S.; Gensini, G.F.; Ferrucci, L.; Abbate, R. Predictors of vitamin B6 and folate concentrations in older persons: The InCHIANTI study. Clin. Chem. 2006, 52, 1318-1324. [CrossRef] [PubMed]

20. Reyman, M.; Verrijn Stuart, A.A.; van Summeren, M.; Rakhshandehroo, M.; Nuboer, R.; de Boer, F.K.; van den Ham, H.J.; Kalkhoven, E.; Prakken, B.; Schipper, H.S. Vitamin D deficiency in childhood obesity is associated with high levels of circulating inflammatory mediators, and low insulin sensitivity. Int. J. Obes. 2014. [CrossRef] [PubMed]

21. Magnus, P.; Irgens, L.M.; Haug, K.; Nystad, W.; Skjaerven, R.; Stoltenberg, C. Cohort profile: The Norwegian Mother and Child Cohort Study (MoBa). Int. J. Epidemiol. 2006, 35, 1146-1150. [CrossRef] [PubMed]

22. Nilsen, R.M.; Vollset, S.E.; Monsen, A.L.; Ulvik, A.; Haugen, M.; Meltzer, H.M.; Magnus, P.; Ueland, P.M. Infant birth size is not associated with maternal intake and status of folate during the second trimester in Norwegian pregnant women. J. Nutr. 2010, 140, 572-579. [CrossRef] [PubMed]

23. O'Broin, S.; Kelleher, B. Microbiological assay on microtitre plates of folate in serum and red cells. J. Clin. Pathol. 1992, 45, 344-347. [CrossRef] [PubMed]

24. Kelleher, B.P.; Broin, S.D. Microbiological assay for vitamin B12 performed in 96-well microtitre plates. J. Clin. Pathol. 1991, 44, 592-595. [CrossRef] [PubMed]

25. Baril, L.; Carmel, R. Comparison of radioassay and microbiological assay for serum folate, with clinical assessment of discrepant results. Clin. Chem. 1978, 24, 2192-2196. [PubMed]

26. Windelberg, A.; Arseth, O.; Kvalheim, G.; Ueland, P.M. Automated assay for the determination of methylmalonic acid, total homocysteine, and related amino acids in human serum or plasma by means of methylchloroformate derivatization and gas chromatography-mass spectrometry. Clin. Chem. 2005, 51, 2103-2109. [CrossRef] [PubMed]

27. Ulvik, A.; Theofylaktopoulou, D.; Midttun, O.; Nygard, O.; Eussen, S.J.; Ueland, P.M. Substrate product ratios of enzymes in the kynurenine pathway measured in plasma as indicators of functional vitamin B-6 status. Am. J. Clin. Nutr. 2013, 98, 934-940. [CrossRef] [PubMed]

28. Fuchs, D.; Weiss, G.; Wachter, H. Neopterin, biochemistry and clinical use as a marker for cellular immune reactions. Int. Arch. Allergy Immunol. 1993, 101, 1-6. [CrossRef] [PubMed]

29. Raitala, A.; Pertovaara, M.; Karjalainen, J.; Oja, S.S.; Hurme, M. Association of interferon-gamma +874 (T / A) single nucleotide polymorphism with the rate of tryptophan catabolism in healthy individuals. Scand. J. Immunol. 2005, 61, 387-390. [CrossRef] [PubMed]

30. Midttun, O.; Hustad, S.; Ueland, P.M. Quantitative profiling of biomarkers related to B-vitamin status, tryptophan metabolism and inflammation in human plasma by liquid chromatography/tandem mass spectrometry. Rapid Commun. Mass Spectrom. 2009, 23, 1371-1379. [CrossRef] [PubMed]

31. R Development Core Team. A Language and Environment for Statistical Computing; R Foundation for Statistical Computing: Vienna, Austria, 2006.

32. Nilsen, R.M.; Vollset, S.E.; Gjessing, H.K.; Skjaerven, R.; Melve, K.K.; Schreuder, P.; Alsaker, E.R.; Haug, K.; Daltveit, A.K.; Magnus, P. Self-selection and bias in a large prospective pregnancy cohort in Norway. Paediatr. Perinat. Epidemiol. 2009, 23, 597-608. [CrossRef] [PubMed] 
33. Visscher, T.L.; Viet, A.L.; Kroesbergen, I.H.; Seidell, J.C. Underreporting of BMI in adults and its effect on obesity prevalence estimations in the period 1998 to 2001. Obesity 2006, 14, 2054-2063. [CrossRef] [PubMed]

34. Hustad, S.; Eussen, S.; Midttun, O.; Ulvik, A.; van de Kant, P.M.; Morkrid, L.; Gislefoss, R.; Ueland, P.M. Kinetic modeling of storage effects on biomarkers related to B vitamin status and one-carbon metabolism. Clin. Chem. 2012, 58, 402-410. [CrossRef] [PubMed]

35. Stamnes Koepp, U.M.; Frost Andersen, L.; Dahl-Joergensen, K.; Stigum, H.; Nass, O.; Nystad, W. Maternal pre-pregnant body mass index, maternal weight change and offspring birthweight. Acta Obstet. Gynecol. Scand. 2012, 91, 243-249. [CrossRef] [PubMed]

36. Metz, J.; McGrath, K.; Bennett, M.; Hyland, K.; Bottiglieri, T. Biochemical indices of vitamin B12 nutrition in pregnant patients with subnormal serum vitamin B12 levels. Am. J. Hematol. 1995, 48, 251-255. [CrossRef] [PubMed]

37. Bruinse, H.W.; van den Berg, H. Changes of some vitamin levels during and after normal pregnancy. Eur. J. Obstet. Gynecol. Reprod. Biol. 1995, 61, 31-37. [CrossRef]

38. Pietrzik, K.F.; Thorand, B. Folate economy in pregnancy. Nutrition 1997, 13, 975-977. [CrossRef]

39. Milman, N.; Byg, K.E.; Bergholt, T.; Eriksen, L.; Hvas, A.M. Cobalamin status during normal pregnancy and postpartum: A longitudinal study comprising 406 Danish women. Eur. J. Haematol. 2006, 76, 521-525. [CrossRef] [PubMed]

40. Shibata, K.; Tachiki, A.; Mukaeda, K.; Fukuwatari, T.; Sasaki, S.; Jinno, Y. Changes in plasma pyridoxal 5'-phosphate concentration during pregnancy stages in Japanese women. J. Nutr. Sci. Vitaminol. 2013, 59, 343-346. [CrossRef] [PubMed]

41. Cikot, R.J.; Steegers-Theunissen, R.P.; Thomas, C.M.; de Boo, T.M.; Merkus, H.M.; Steegers, E.A. Longitudinal vitamin and homocysteine levels in normal pregnancy. Br. J. Nutr. 2001, 85, 49-58. [CrossRef] [PubMed]

42. Cunningham, P.; McDermott, L. Long chain PUFA transport in human term placenta. J. Nutr. 2009, 139, 636-639. [CrossRef] [PubMed]

43. Ueland, P.M.; Refsum, H.; Schneede, J. Determinants of plasma homocysteine. In Homocysteine and Vascular Disease; Robinson, K., Ed.; Kluwer Academic Publishers: Dordrecht, The Netherlands, 2000; pp. 59-84.

44. Velzing-Aarts, F.V.; Holm, P.I.; Fokkema, M.R.; van der Dijs, F.P.; Ueland, P.M.; Muskiet, F.A. Plasma choline and betaine and their relation to plasma homocysteine in normal pregnancy. Am. J. Clin. Nutr. 2005, 81, 1383-1389. [PubMed]

45. Savage, D.G.; Lindenbaum, J.; Stabler, S.P.; Allen, R.H. Sensitivity of serum methylmalonic acid and total homocysteine determinations for diagnosing cobalamin and folate deficiencies. Am. J. Med. 1994, 96, $239-246$. [CrossRef]

46. Greibe, E.; Andreasen, B.H.; Lildballe, D.L.; Morkbak, A.L.; Hvas, A.M.; Nexo, E. Uptake of cobalamin and markers of cobalamin status: A longitudinal study of healthy pregnant women. Clin. Chem. Lab. Med. 2011, 49, 1877-1882. [CrossRef] [PubMed]

47. Murphy, M.M.; Molloy, A.M.; Ueland, P.M.; Fernandez-Ballart, J.D.; Schneede, J.; Arija, V.; Scott, J.M. Longitudinal study of the effect of pregnancy on maternal and fetal cobalamin status in healthy women and their offspring. J. Nutr. 2007, 137, 1863-1867. [PubMed]

48. Bjorke-Monsen, A.L.; Roth, C.; Magnus, P.; Midttun, O.; Nilsen, R.M.; Reichborn-Kjennerud, T.; Stoltenberg, C.; Susser, E.; Vollset, S.E.; Ueland, P.M. Maternal B vitamin status in pregnancy week 18 according to reported use of folic acid supplements. Mol. Nutr. Food Res. 2013, 57, 645-652. [CrossRef] [PubMed]

49. Marques, A.H.; Bjorke-Monsen, A.L.; Teixeira, A.L.; Silverman, M.N. Maternal stress, nutrition and physical activity: Impact on immune function, CNS development and psychopathology. Brain Res. 2015. [CrossRef] [PubMed]

50. Schrocksnadel, K.; Widner, B.; Bergant, A.; Neurauter, G.; Schrocksnadel, H.; Fuchs, D. Tryptophan degradation during and after gestation. Adv. Exp. Med. Biol. 2003, 527, 77-83. [PubMed]

51. Fuith, L.C.; Fuchs, D.; Hausen, A.; Hetzel, H.; Reibnegger, G.; Werner, E.R.; Wachter, H. Neopterin, a marker of cell-mediated immune activation in human pregnancy. Int. J. Fertil. 1991, 36, 372-375. [PubMed]

52. Von Versen-Hoeynck, F.M.; Hubel, C.A.; Gallaher, M.J.; Gammill, H.S.; Powers, R.W. Plasma levels of inflammatory markers neopterin, sialic acid, and C-reactive protein in pregnancy and preeclampsia. Am. J. Hypertens. 2009, 22, 687-692. [CrossRef] [PubMed] 
53. Navolan, D.B.; Vladareanu, S.; Lahdou, I.; Ciohat, I.; Kleist, C.; Grigoras, D.; Vladareanu, R.; Terness, P.; Sas, I. Early pregnancy serum neopterin concentrations predict spontaneous preterm birth in asymptomatic pregnant women. J. Perinat. Med. 2016. [CrossRef] [PubMed]

54. Nilsen, R.M.; Vollset, S.E.; Gjessing, H.K.; Magnus, P.; Meltzer, H.M.; Haugen, M.; Ueland, P.M. Patterns and predictors of folic acid supplement use among pregnant women: The Norwegian Mother and Child Cohort Study. Am. J. Clin. Nutr. 2006, 84, 1134-1141. [PubMed]

55. Theofylaktopoulou, D.; Ulvik, A.; Midttun, O.; Ueland, P.M.; Vollset, S.E.; Nygard, O.; Hustad, S.; Tell, G.S.; Eussen, S.J. Vitamins B2 and B6 as determinants of kynurenines and related markers of interferon-gamma-mediated immune activation in the community-based Hordaland Health Study. Br. J. Nutr. 2014, 112, 1065-1072. [CrossRef] [PubMed]

56. Lepski, S.; Brockmeyer, J. Impact of dietary factors and food processing on food allergy. Mol. Nutr. Food Res. 2013, 57, 145-152. [CrossRef] [PubMed]

57. Ulvik, A.; Midttun, O.; Pedersen, E.R.; Eussen, S.J.; Nygard, O.; Ueland, P.M. Evidence for increased catabolism of vitamin B-6 during systemic inflammation. Am. J. Clin. Nutr. 2014, 100, 250-255. [CrossRef] [PubMed]

58. Chiang, E.P.; Smith, D.E.; Selhub, J.; Dallal, G.; Wang, Y.C.; Roubenoff, R. Inflammation causes tissue-specific depletion of vitamin B6. Arthritis Res. Ther. 2005, 7, R1254-R1262. [CrossRef] [PubMed]

59. Torsvik, I.K.; Ueland, P.M.; Markestad, T.; Midttun, O.; Monsen, A.L. Motor development related to duration of exclusive breastfeeding, B vitamin status and B12 supplementation in infants with a birth weight between 2000-3000 g, results from a randomized intervention trial. BMC Pediatr. 2015, 15, 218. [CrossRef] [PubMed]

(C) 2016 by the authors; licensee MDPI, Basel, Switzerland. This article is an open access article distributed under the terms and conditions of the Creative Commons Attribution (CC-BY) license (http:/ / creativecommons.org/licenses/by/4.0/). 